\title{
Hypoxic mast cells accelerate the proliferation, collagen accumulation and phenotypic alteration of human lung fibroblasts
}

\author{
XIANG WANG, LIANJUN LIN, XIAOYU CHAI, YANPING WU, YONG LI and XINMIN LIU \\ Department of Geriatrics, Peking University First Hospital, Beijing 100034, P.R. China
}

Received May 12, 2019; Accepted October 9, 2019

DOI: $10.3892 / \mathrm{ijmm} .2019 .4400$

\begin{abstract}
Pulmonary vascular remodeling and fibrosis are the critical pathological characteristics of hypoxic pulmonary hypertension. Our previous study demonstrated that hypoxia is involved in the functional alteration of lung fibroblasts, but the underlying mechanism has yet to be fully elucidated. The aim of the present study was to investigate the effect of mast cells on the proliferation, function and phenotype of fibroblasts under hypoxic conditions. Hypoxia facilitated proliferation and the secretion of proinflammatory cytokines, including tumor necrosis factor (TNF)- $\alpha$ and interleukin (IL)-6, in human mast cells (HMC-1). RNA sequencing identified 2,077 upregulated and 2,418 downregulated mRNAs in human fetal lung fibroblasts (HFL-1) cultured in hypoxic conditioned medium from HMC-1 cells compared with normoxic controls, which are involved in various pathways, including extracellular matrix organization, cell proliferation and migration. Conditioned medium from hypoxic HMC-1 cells increased the proliferation and migration capacity of HFL-1 and triggered phenotypic transition from fibroblasts to myofibroblasts. A greater accumulation of collagen type I and III was also observed in an HFL-1 cell culture in hypoxic conditioned medium from HMC-1 cells, compared with HFL-1 cells cultured in normoxic control medium. The expression of
\end{abstract}

Correspondence to: Professor Xinmin Liu, Department of Geriatrics, Peking University First Hospital, 8 Xishiku Street, Beijing 100034, P.R. China

E-mail: 1xm2128@163.com

Abbreviations: TNF- $\alpha$, tumor necrosis factor- $\alpha$; IL, interleukin; MMP, matrix metalloproteinase; COPD, chronic obstructive pulmonary disease; IMDM, Iscove's modified Dulbecco's medium; FBS, fetal bovine serum; CCK8, Cell Counting Kit-8; ELISA, enzyme-linked immunosorbent assay; TIMP, tissue inhibitor of metalloproteinase; COL I, collagen type I; COL III, collagen type III; HIF, hypoxia-inducible factor; $\mathrm{PAH}$, pulmonary arterial hypertension; $\alpha$-SMA, $\alpha$-smooth muscle actin; GO, Gene Ontology; KEGG, Kyoto Encyclopedia of Genes and Genomes; H\&E, hematoxylin and eosin; PBS, phosphate-buffered saline; DAPI, 4',6-diamidino-2-phenylindole

Key words: lung fibroblasts, mast cells, hypoxia, conditioned medium, proliferation, collagen, phenotypic alteration matrix metalloproteinase (MMP)-9 and MMP-13 was upregulated in HFL-1 cells grown in hypoxic conditioned medium from HMC-1 cells. Similar pathological phenomena, including accumulation of mast cells, activated collagen metabolism and vascular remodeling, were observed in a hypoxic rat model. The results of the present study provide direct evidence that the multiple effects of the hypoxic microenvironment and mast cells on fibroblasts contribute to pulmonary vascular remodeling, and this process appears to be among the most important mechanisms underlying hypoxic pulmonary hypertension.

\section{Introduction}

Pulmonary hypertension generally results from hypoxic lung diseases, such as chronic obstructive pulmonary disease (COPD), cystic fibrosis and bronchiectasis (1). Chronic hypoxia results in pulmonary hypertension, which is characterized by progressively elevated pulmonary arterial pressure, increased right ventricular afterload leading to right ventricular hypertrophy, ultimately resulting in heart failure $(2,3)$. Pulmonary hypertension is independently associated with increased morbidity and reduced survival in patients suffering from hypoxic lung disease. Pulmonary vascular remodeling accompanies and is considered to be the primary cause of pulmonary hypertension by increasing pulmonary vascular resistance (4).

The pulmonary vascular wall is a heterogeneous three-layered structure composed of adventitia, media and intima. Pulmonary artery remodeling is a complicated pathological process involving disorders of all three layers of the vascular wall, including adventitial thickening, medial hypertrophy, neointima formation and plexiform lesions (5). Resident adventitial fibroblasts are considered to be the principal sensor tissue of the vessel wall in response to stress or injury, and they can be activated and undergo phenotypic changes to exhibit various structural and functional alterations $(6,7)$. Our previous study demonstrated that hypoxia induces functional alterations in lung fibroblasts and it may be involved in pulmonary vascular remodeling (8). Evidence from recent studies indicates that mast cells are also associated with non-allergic chronic lung diseases. The presence of abundant perivascular mast cells, as well as increased secretion of inflammatory substances, was observed in the lungs of patients with pulmonary arterial hypertension (PAH) and experimental models of pulmonary hypertension $(9,10)$. 
Despite evidence showing that mast cells contribute to vascular remodeling and the development of pulmonary hypertension under pathological conditions, the underlying mechanism has not been fully elucidated.

The aim of the present study was to investigate the effect of mast cells on the viability, function and phenotype of fibroblasts under hypoxic conditions. It was hypothesized that hypoxia-activated mast cells affect the characteristics of lung fibroblasts and are involved in pulmonary vascular remodeling. To test this hypothesis, the viability and secretion of cytokines by human mast cells (HMC-1) under hypoxia were first examined. Subsequently, the effects of hypoxic conditioned medium from HMC-1 cells on human fetal lung fibroblasts (HFL-1) were examined using RNA sequencing (RNA-seq) analysis and molecular biology experiments. Finally, using a rat model of hypoxic pulmonary hypertension, the distribution of mast cells, extracellular matrix remodeling and myofibroblast transition in the lung were explored.

\section{Materials and methods}

Cell culture. The human mast cell line HMC-1 (Cellbio) was cultured in Iscove's Modified Dubecco's Medium (IMDM; Gibco; Thermo Fisher Scientific, Inc.) supplemented with $10 \%$ fetal bovine serum (FBS; Gibco; Thermo Fisher Scientific, Inc.), $100 \mathrm{mg} / \mathrm{ml}$ streptomycin and $100 \mathrm{U} / \mathrm{ml}$ penicillin (Sigma-Aldrich; Merck KGaA). HMC-1 cells were incubated at $37^{\circ} \mathrm{C}$ in a $5 \% \mathrm{CO}_{2}$ atmosphere at $95 \%$ relative humidity. For hypoxic exposure, HMC-1 cells were placed in a modulator incubator in an atmosphere of $94 \% \mathrm{~N}_{2}, 5 \% \mathrm{CO}_{2}$ and $1 \% \mathrm{O}_{2}$, and normoxic conditions were defined as $21 \% \mathrm{O}_{2}$. Subsequently, cells and supernatants were collected for subsequent experiments. For the preparation of conditioned medium, the supernatants were centrifuged for $10 \mathrm{~min}$ at $500 \mathrm{x} \mathrm{g}$ at room temperature to remove detached cells and used directly. HFL-1 cells (Type Culture Collection Center, Chinese Academy of Sciences) were cultured in Ham's F-12K (Kaighn's) medium with $10 \% \mathrm{FBS}, 100 \mathrm{mg} / \mathrm{ml}$ streptomycin and $100 \mathrm{U} / \mathrm{ml}$ penicillin until confluent.

Cell proliferation assay. Cells at $70 \%$ confluence were serum-starved in $0.1 \%$ FBS for $24 \mathrm{~h}$ for synchronization, plated at $5 \times 10^{3}$ cells per well in 96-well plates and cultured for $6 \mathrm{~h}$ at $37^{\circ} \mathrm{C}$ in $5 \% \mathrm{CO}_{2}$ in order to allow the cells to attach. Subsequently, HMC-1 cells were incubated with fresh IMDM (Gibco; Thermo Fisher Scientific, Inc.) containing 10\% FBS under hypoxic conditions, and HFL-1 cells were cultured in conditioned medium from hypoxic or normoxic HMC-1 cells for different times. The Cell Counting Kit-8 (CCK-8, Dojindo Molecular Technologies, Inc.) was used to determine cell proliferation at various time points. For the CCK- 8 assay, cells were incubated with $10 \mu \mathrm{l}$ CCK- 8 solution for $1 \mathrm{~h}$, and absorbance was measured at $450 \mathrm{~nm}$.

Measurement of cytokines. Secreted cytokines from HMC-1 cells, including tumor necrosis factor (TNF)- $\alpha$ (cat. no. KE00068, ProteinTech Group, Inc.), interleukin (IL)-1 $\beta$ (cat. no. KE00021, ProteinTech Group, Inc.), IL-6 (cat. no. KE00007, ProteinTech Group, Inc.) and IL-15 (cat. no. KE00102, ProteinTech Group, Inc.) were measured with the use of ELISA kits. ELISA was performed according to the manufacturer's protocol (ProteinTech Group, Inc.). Briefly, the supernatants or standards were added to 96-well microplates and incubated for $60 \mathrm{~min}$ at room temperature. After washing 3 times with wash buffer, the corresponding detection antibodies were added for $60 \mathrm{~min}$ at $37^{\circ} \mathrm{C}$. The plate was washed with wash buffer, $100 \mu 1$ horseradish peroxidase (HRP)-conjugated antibodies were added and the reaction was incubated for $30 \mathrm{~min}$ at $37^{\circ} \mathrm{C}$ in a light-resistant container. Subsequently, $100 \mu 1$ tetramethylbenzidine substrate (TMB) solution was added and incubated for $15 \mathrm{~min}$ at $37^{\circ} \mathrm{C}$. Finally, stop solution was added to each well to terminate the reaction. Absorbance was calculated by measurement at $450 \mathrm{~nm}$, and the levels of cytokines were calculated using the standard curve.

$R N A$ extraction and reverse transcription-quantitative polymerase chain reaction ( $R T-q P C R)$ analysis. Total RNA was extracted from HFL-1 and HMC-1 cells by use of TRIzol reagent (Tiangen), and cDNA was acquired by use of reverse transcriptase (Thermo Fisher Scientific, Inc.). qPCR with the use of Maxima SYBR-Green I qPCR Master Mix (Thermo Fisher Scientific, Inc.) was performed as follows: $95^{\circ} \mathrm{C}$ for $5 \mathrm{~min}$, followed by $35 \mathrm{cycles}$ at $95^{\circ} \mathrm{C}$ for $30 \mathrm{sec}, 60^{\circ} \mathrm{C}$ for $30 \mathrm{sec}$ and $72^{\circ} \mathrm{C}$ for $1 \mathrm{~min}$. cDNA was amplified with the primer sequences for TNF- $\alpha$ (forward 5'-ccttcctctctccagatgtttc-3', reverse 5'-cccggtctcccaaataaataca-3'), IL-1 $\beta$ (forward 5'-cctggactttcctgttgtctac-3', reverse 5'-aagtgagtaggagaggtgagag-3'), IL-6 (forward 5'-cagctatgaactcettctccac-3', reverse 5'-cgtcgaggatgtaccgaattt-3'), IL-15 (forward 5'-ccactgtgtccggaattgat-3', reverse 5'-gaacccaccagaaggaagaaa-3'), matrix metalloproteinase (MMP)-9 (forward 5'-ggtaaggagtactcgacctgta-3', reverse 5'-cggcactgaggaatgatctaag-3'), MMP-13 (forward 5'-ggcgacttctacccatttga-3', reverse 5'-cttggagtggtcaagacctaag-3'), tissue inhibitor of metalloproteinase 1 (TIMP-1; forward 5'-gatggtgggtggatgagtaatg-3', reverse $5^{\prime}$-gggttctctggtgtctctct-3'), collagen type I (forward 5'-cccagccaagaactggtatag-3', reverse 5'-ggtgatgttctgagaggcatag-3') and III (forward 5'-ttggaagtcctggtccaaag-3', reverse 5'-caccaccttcaccettatctc-3'), $\alpha$-smooth muscle actin ( $\alpha$-SMA; forward 5'-ccgaatgcagaaggagatca-3', reverse 5 '-gtggacagagaggccaggat-3') and $\beta$-tubulin (forward 5 '-gaggctgagagcaacatgaa-3', reverse 5 '-cagttgagtaagacggctaagg-3'). For quantification, target gene expression was normalized to that of $\beta$-actin in each sample. Data analysis involved the $-\Delta \Delta \mathrm{Cq}$ method (11).

Western blot analysis. Total proteins were extracted from treated cells using lysis buffer containing protease inhibitors (Beyotime Institute of Biotechnology). The protein concentration of the lysates was quantified with a bicinchoninic acid assay (Beyotime Institute of Biotechnology). Total protein in lysates (50 $\mu \mathrm{g}$ per lane) was separated by $10 \%$ SDS-PAGE and then transferred to nitrocellulose membranes (Thermo Fisher Scientific, Inc.). The membranes were incubated with primary antibodies, including polyclonal rabbit anti-hypoxia inducible factor (HIF)-1 $\alpha$ (dilution 1:1,000; cat. no. 20960-1-AP, ProteinTech Group, Inc.), polyclonal rabbit anti-collagen type I (dilution 1:1,000; cat. no. 14695-1-AP, ProteinTech Group, Inc.), polyclonal rabbit anti-collagen type III (dilution 1:1,000; cat. no. 22734-1-AP, ProteinTech Group, Inc.), polyclonal rabbit 
anti-MMP-9 (dilution 1:1,000; cat. no. 10375-2-AP, ProteinTech Group, Inc.), polyclonal rabbit anti-MMP-13 (dilution 1:1,000; cat. no. 18165-1-AP, ProteinTech Group, Inc.), polyclonal rabbit anti-TIMP-1 (dilution 1:1,000; cat. no. 16644-1-AP, ProteinTech Group, Inc.), polyclonal rabbit anti- $\alpha$-SMA (dilution 1:1,000; cat. no. 55135-1-AP, ProteinTech Group, Inc.) or polyclonal rabbit anti- $\beta$-tubulin (dilution 1:1,000; cat. no. 10068-1-AP, ProteinTech Group, Inc.). After washing, the membranes were incubated with HRP-conjugated secondary antibody (mouse anti-rabbit IgG, dilution 1:5,000; cat. no. sc-2357, Santa Cruz Biotechnology, Inc.). The blots were observed using an enhanced chemiluminescence western blotting detection system (Bio-Rad Laboratories, Inc.).

RNA-seq and data analysis. RNA integrity was examined by $1 \%$ formaldehyde denaturing gel electrophoresis. RNA-seq was performed by Illumina HiSeq sequencer (Illumina, Inc.) at CapitalBio Corporation. The raw data of RNA-seq were aligned to the human genome version hg19. Differentially expressed genes with absolute fold change $>2.0$ and $\mathrm{P}<0.05$ were considered statistically significant in the RNA-seq analysis. To better understand the roles of the differentially expressed mRNAs, biological process analysis was performed using the Gene Ontology (GO; www.geneontology.org) and Kyoto Encyclopedia of Genes and Genomes (KEGG; http://www.genome.jp/kegg/) databases.

Migration assay. HFL-1 cells were seeded at $5 \times 10^{6}$ cells per well in 6-well plates and then incubated at $37^{\circ} \mathrm{C}$ in $5 \% \mathrm{CO}_{2}$ until confluence. Following preincubation with F12K medium with $0.1 \%$ FBS for $24 \mathrm{~h}$ for synchronization, a scratch was created in each well by using a $200-\mu 1$ pipette tip. The cells were gently washed twice with PBS and cultured in normoxic and hypoxic conditioned medium from $\mathrm{HMC}-1$ cells at $37^{\circ} \mathrm{C}$ in $5 \% \mathrm{CO}_{2}$ for another $24 \mathrm{~h}$. Images of the cells along the scratch were captured at x100 magnification using an inverted optical microscope. The migrated cells were then counted to evaluate the migration efficiency of the HFL-1 cells.

Immunofluorescence analysis. The slides of HFL-1 cells were fixed in $4 \%$ paraformaldehyde for $30 \mathrm{~min}$ at room temperature. After washing with PBS three times, they were permeabilized with $0.1 \%$ Triton $\mathrm{X}-100$ in PBS for $5 \mathrm{~min}$ on ice and then blocked with $3 \%$ BSA in PBS for 30 min at room temperature. Subsequently, HFL-1 cells were incubated with rabbit anti- $\alpha$-SMA antibody (dilution, 1:1,000; cat. no. 55135-1-AP, ProteinTech Group, Inc.) or corresponding serum as a negative control at $4^{\circ} \mathrm{C}$ overnight. Unbound antibodies were removed by washing with PBS three times, and the slides were incubated with goat anti-rabbit IgG-FITC antibody (1:500 dilution; cat. no. ab6717, Abcam) in the dark for $60 \mathrm{~min}$. After washing with PBS three times, HFL-1 cells were stained with 4',6-diamidino-2-phenylindole (DAPI; $10 \mu \mathrm{g} / \mathrm{ml}$, Sigma-Aldrich; Merck KGaA) in the dark for $5 \mathrm{~min}$, and finally examined under a Zeiss LSM laser confocal microscope (Carl Zeiss AG).

Animal experimental protocol. All animal experiments were performed according to the Guide for the Care and Use of Laboratory Animals and approved by the Peking
University First Hospital Ethical Review Committee (approval no. J201533). Male Sprague-Dawley rats $(n=12$, age, 8-10 weeks, weight, $220 \pm 10 \mathrm{~g}$ ) were obtained from Vital River Laboratory Animal Technology Co. Ltd. and randomly divided into normoxic and hypoxic groups ( $n=6 /$ group). A hypoxic rat model was established as described in our previous study (8). Briefly, rats in the normoxic group were placed in a chamber with normobaric normoxia $\left(21 \% \mathrm{O}_{2}\right)$, while rats in the hypoxic group were placed in an automatic hypobaric chamber $\left(10 \% \mathrm{O}_{2}\right)$ continuously for 3 weeks. All rats were housed in an air-conditioned room $\left(22-24^{\circ} \mathrm{C}\right)$ with a 12-h light/dark cycle and free access to food and water. At the end of the treatment period, the rats were anesthetized using sodium pentobarbital (50 mg/kg, i.p.) and cervical dislocation was performed quickly by an experienced researcher; no rats exhibited clinical signs of suffering, and death was verified by the lack of heartbeat and breathing. After euthanizing the anesthetized rats, the lungs were harvested for hematoxylin and eosin (H\&E) staining and immunohistochemistry.

Histological analysis and immunohistochemistry assay. The lung specimens were fixed in $4 \%$ paraformaldehyde, embedded in paraffin and cut into $5-\mu \mathrm{m}$ sections. Subsequently, the sections were mounted on glass slides and deparaffinized. Serial sections were stained with H\&E for morphological analysis using a routine protocol. Mast cells were stained with toluidine blue (Sigma-Aldrich; Merck KGaA) in 1\% sodium chloride. For immunohistochemistry staining, paraffin sections were autoclaved in a citrate buffer ( $\mathrm{pH}$ 6.0) and blocked in $3 \% \mathrm{H}_{2} \mathrm{O}_{2}$. The slides were incubated at $4^{\circ} \mathrm{C}$ overnight with primary rabbit antibodies, including anti-collagen typeI(dilution, 1:1,000; cat. no. 14695-1-AP, ProteinTech Group, Inc.), anti-collagen type III (dilution, 1:200; cat. no. 22734-1-AP, ProteinTech Group, Inc.), anti-MMP-9 (dilution, 1:200; cat. no. 10375-2-AP, ProteinTech Group, Inc.), anti-MMP-13 (dilution, 1:200; cat. no. 18165-1-AP, ProteinTech Group, Inc.), anti-TIMP-1 (dilution, 1:100; cat. no. 16644-1-AP, ProteinTech Group, Inc.). Subsequently, the slides were incubated with HRP-conjugated goat anti-rabbit IgG secondary antibody (provided at working dilution, cat. no. PV-6001; Zhongshan Golden Bridge Biotechnology). The immune complexes were detected by a 3,3'-diaminobenzidine detection system (Zhongshan Golden Bridge Biotechnology). The sections were counterstained with hematoxylin and dehydrated before mounting. The stained sections were observed using an optical microscope.

Statistical analysis. Statistical analysis involved the use of SPSS 16.0 (SPSS, Inc.). Quantitative data are presented as the mean \pm standard deviation of at least 3 independent experiments. Student's t-test or one-way ANOVA followed by Scheffe's post hoc test was used to compare multiple groups. $\mathrm{P}<0.05$ was considered to indicate statistically significant differences.

\section{Results}

Increased proliferation of HMC-1 cells under hypoxic conditions. To examine the effects of hypoxia on the viability of human mast cells, HMC-1 cells were cultured under hypoxic conditions and their proliferation was detected. As 
A

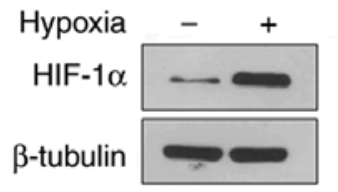

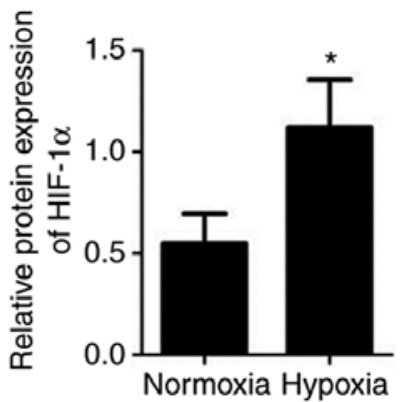

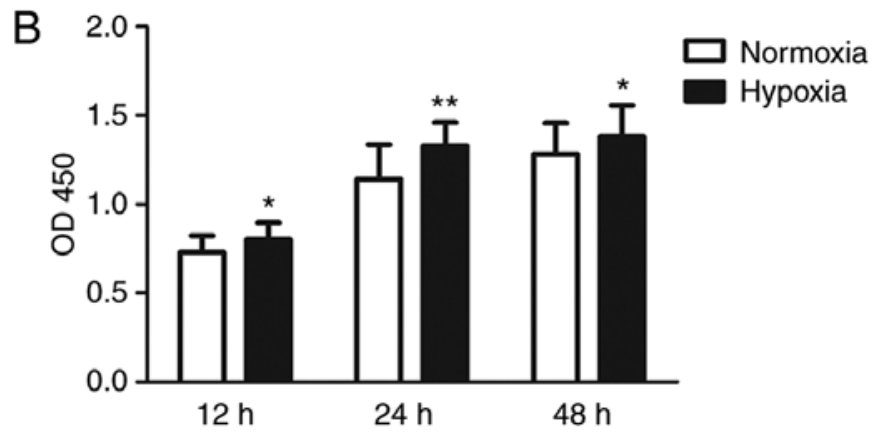

Figure 1. Effects of hypoxia on the proliferation of HMC-1 cells. (A) Following culture under hypoxic conditions, the expression of HIF-1 $\alpha$ in HMC-1 cells was determined by western blotting and used to confirm that cells exist within a hypoxic environment. (B) The proliferation of HMC-1 cells under hypoxic and normoxic conditions was examined by the Cell Counting Kit- 8 assay for the indicated time periods. There were 4 biological replicates/condition. Error bars represent the standard deviation. ${ }^{*} \mathrm{P}<0.05,{ }^{* *} \mathrm{P}<0.01$. HMC-1, human mast cells; HIF-1 $\alpha$, hypoxia inducible factor-1 $\alpha$; OD, optical density.

A

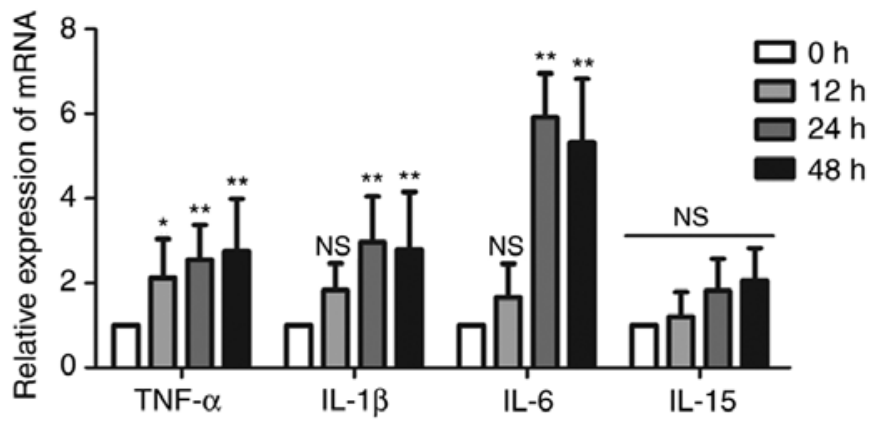

B

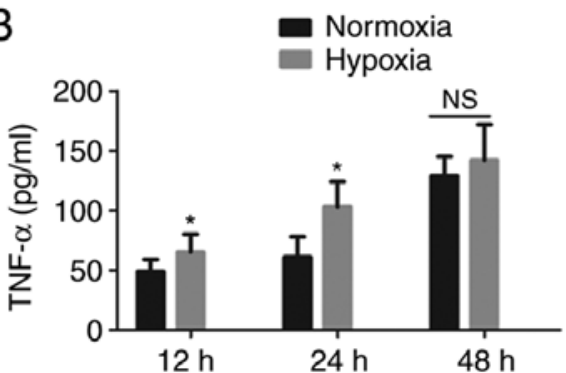

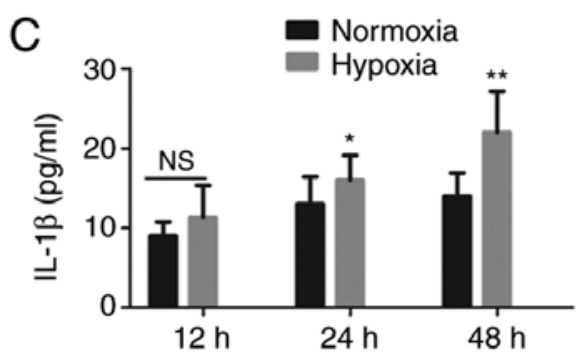
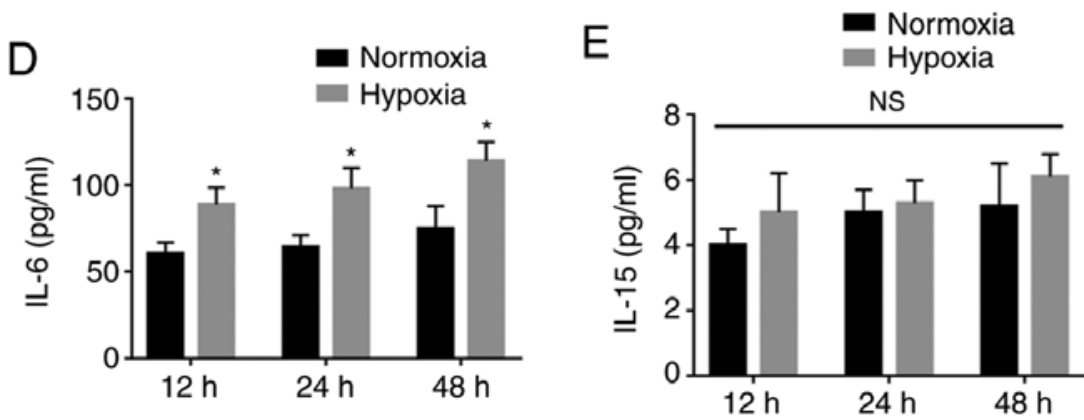

Figure 2. Effects of hypoxia on the secretion of cytokines by HMC-1 cells. (A) HMC-1 cells were cultured under hypoxic conditions for the indicated time periods and then subjected to reverse transcription-quantitative polymerase chain reaction to detect the expression of cytokines IL-1 $\beta$, IL-6, IL-15 and TNF- $\alpha$. $\beta$-tubulin was used as an internal control. (B-E) Following culture under hypoxic conditions, the levels of the secreted cytokines IL-1 $\beta$, IL-6, IL-15 and TNF- $\alpha$ in the conditioned medium from HMC-1 cells were determined by ELISA. There were 4-6 biological replicates/condition. Error bars depict the standard deviation. ${ }^{*} \mathrm{P}<0.05,{ }^{* *} \mathrm{P}<0.01$, NS, not significant. IL, interleukin; TNF, tumor necrosis factor; HMC-1, human mast cells.

shown in Fig. 1A, exposure to hypoxia significantly increased the expression of HIF-1 $\alpha$, suggesting that HMC-1 cells exist within a hypoxic environment. Compared to normoxic conditions, hypoxia significantly increased the proliferation of HMC- 1 cells by 10.2 and $16.2 \%$ at 12 and $24 \mathrm{~h}$, respectively (Fig. 1B). However, there was no significant difference between the hypoxic and normoxic groups at $48 \mathrm{~h}$.

Effects of hypoxia on the secretion of cytokines by HMC-1 cells. To explore the changes in cytokines in human mast cells under hypoxia, we next cultured HMC-1 cells under hypoxia for the indicated time periods. The expression of IL-1 $\beta$ and IL-6 increased substantially after $12 \mathrm{~h}$ and peaked after $24 \mathrm{~h}$, by almost three- and six-fold, respectively, in the medium of HMC-1 cells exposed to hypoxia compared with the normoxic controls. The expression of TNF- $\alpha$ mRNA was increased in a time-dependent manner, while the expression of IL-15 mRNA did not exhibit obvious changes (Fig. 2A). Subsequently, the resulting supernatant from HMC-1 cells under different conditions was collected and the levels of cytokines were measured. As shown in Fig. 2B-E, the levels of IL-1 $\beta$, IL- 6 and TNF- $\alpha$ were higher in the hypoxic medium of HMC-1 cells compared with the normoxic control medium, while the IL-15 content remained unchanged.

RNA-seq analysis of HFL-1 cells cultured in conditioned medium from HMC-1 cells. To evaluate the effects of mast cells on lung fibroblasts under hypoxia, the HFL-1 cells were cultured in hypoxic and normoxic conditioned medium from HMC-1 cells and RNA-seq analysis was performed to compare 
the global mRNA expression profile. A box plot was drawn to visualize the distribution of the intensities of all the samples after normalization and the distribution of $\log 2$ ratios was found to be similar in all the samples (Fig. 3A). Hierarchical clustering revealed that there is a distinguishable mRNA expression profiling between the hypoxic group and controls, and microarray identified 4,495 differentially expressed mRNAs in total (fold change $>2.0$, P-value $<0.05$ ), including 2,077 upregulated and 2,418 downregulated in HFL-1 cells cultured in hypoxic conditioned medium (Fig. 3B). The top 40 differentially expressed mRNA are listed in Table I. Additionally, scatter and volcano plots were constructed to visualize the significant variation between the two groups (Fig. 3C and D). To understand the function of these differentially expressed genes, we performed a bioinformatic pathway analysis of GO and KEGG data. As shown in Fig. 3E, the highest enriched GO pathways targeted by differentially expressed genes were extracellular matrix organization and cell migration, among others. Moreover, the potential module function was predicted by KEGG pathway analysis. Various pathways, including extracellular matrix organization, cytokine signaling in immune system and collagen formation, which are closely associated with pulmonary hypertension, were significantly enriched in HFL-1 cells cultured in hypoxic conditioned medium from HMC-1 cells (Fig. 3F).

Hypoxic conditioned medium from HMC-1 cells promotes the proliferation and migration of HFL-1 cells. The proliferation and migration of lung fibroblasts plays an important role in hypoxic pulmonary hypertension. To assess the effect of the secretion of paracrine factors from mast cells on human lung fibroblasts, HFL-1 cells were cultured in hypoxic and normoxic conditioned medium from HMC-1 cells and their proliferation and the migration were examined. Compared with normoxic conditioned medium from HMC-1 cells, hypoxic conditioned medium significantly increased the proliferation of HFL-1 cells (Fig. 4A). The migration of HFL-1 cells was examined by scratch assay and the results revealed that treatment with hypoxic conditioned medium significantly facilitated the migration of HFL-1 cells (Fig. 4B).

Hypoxic conditioned medium from HMC-1 cells regulates the production of collagen and collagenase in HFL-1 cells. To further characterize the role of mast cells in fibrogenesis, the expression of collagen I and III was first detected in HFL-1 cells under different culture conditions. The mRNA expression levels of collagen type I and III were both higher in the hypoxic conditioned medium compared with those in the control medium, and the protein expression displayed the same trend (Fig. 5). The expression of the proteolytic enzymes MMP-9 and MMP-13 at the mRNA and protein levels was upregulated in HFL-1 cells treated with hypoxic conditioned medium from HMC-1 cells, while TIMP-1 expression remained unchanged.

Hypoxic conditioned medium from HMC-1 cells induces the transition from fibroblast to myofibroblast in HFL-1 cells. We investigated whether human mast cells affect the constitutive characteristics of lung fibroblasts under hypoxia. The expression of $\alpha$-SMA mRNA and protein was upregulated
Table I. Top 20 upregulated and downregulated mRNAs in human fetal lung fibroblasts (HFL-1) cultured in hypoxic conditioned medium from human mast cells (HMC-1) and normoxic controls.

\begin{tabular}{|c|c|c|}
\hline mRNAs & P-value & $\log 2$ fold change \\
\hline TNFSF8 & 0.000 & 9.4533 \\
\hline IL36RN & 0.020 & 9.1130 \\
\hline CYP19A1 & 0.000 & 8.5295 \\
\hline BEST3 & 0.001 & 7.0775 \\
\hline IL24 & 0.000 & 7.0084 \\
\hline WTAPP1 & 0.000 & 6.7566 \\
\hline STC1 & 0.000 & 6.6111 \\
\hline ESM1 & 0.002 & 6.6003 \\
\hline CCL3L3 & 0.002 & 6.5711 \\
\hline MMP10 & 0.002 & 6.5556 \\
\hline IL36B & 0.002 & 6.5535 \\
\hline THBD & 0.000 & 6.4407 \\
\hline CSF2 & 0.026 & 6.3719 \\
\hline DCSTAMP & 0.000 & 6.3002 \\
\hline IL1B & 0.000 & 6.2982 \\
\hline SHISA2 & 0.005 & 6.2159 \\
\hline LCE1C & 0.000 & 6.1842 \\
\hline EREG & 0.000 & 6.1640 \\
\hline PTGS2 & 0.000 & 6.1336 \\
\hline SERPINB2/10 & 0.000 & 6.0740 \\
\hline
\end{tabular}

B, Downregulated mRNAs

\begin{tabular}{|c|c|c|}
\hline mRNAs & P-value & $\log 2$ fold change \\
\hline MUC19 & 0.038 & -8.1010 \\
\hline USH2A & 0.000 & -7.3792 \\
\hline TACR3 & 0.000 & -7.3221 \\
\hline $\mathrm{ADH} 1 \mathrm{~B}$ & 0.000 & -7.0604 \\
\hline RSPO2 & 0.000 & -6.8458 \\
\hline CDSN & 0.000 & -6.6503 \\
\hline ITIH5 & 0.000 & -6.6445 \\
\hline SMTNL2 & 0.000 & -6.6222 \\
\hline RNU2-52P & 0.000 & -6.5828 \\
\hline PTGDR2 & 0.000 & -6.5349 \\
\hline ASTN1 & 0.000 & -6.5022 \\
\hline SPTB & 0.000 & -6.4692 \\
\hline OGN & 0.000 & -6.4411 \\
\hline LAD & 0.000 & -6.3950 \\
\hline NFE2 & 0.000 & -6.3828 \\
\hline GPR20 & 0.000 & -6.2826 \\
\hline MUC22 & 0.000 & -6.2617 \\
\hline TMEM37 & 0.000 & -6.2537 \\
\hline ABCA9 & 0.000 & -6.2412 \\
\hline DNAH2 & 0.000 & -6.2343 \\
\hline
\end{tabular}



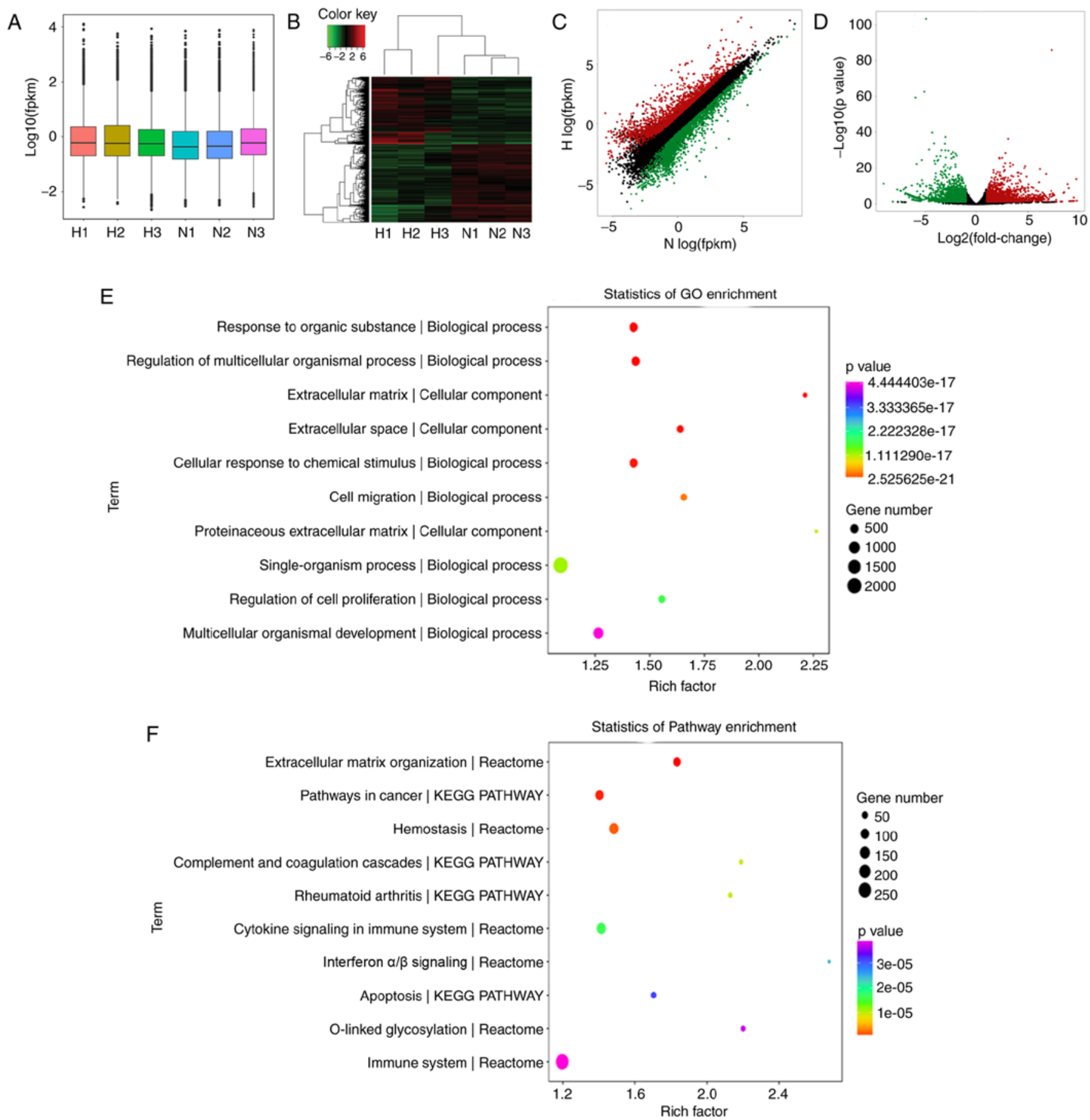

Figure 3. Differential expression of mRNA in HFL-1 cells cultured in hypoxic and normoxic conditioned medium from HMC-1 cells. (A) Box plot of RNA sequencing dataset after normalization. (B) Hierarchical clustering of differentially expressed mRNAs in HFL-1 hypoxic group and normoxic controls (C) Scatter plots demonstrated differential mRNA expression between hypoxic and normoxic samples. The red circles indicate upregulated genes, the green circles represent downregulated genes, and black circles indicate unchanged genes. (D) Volcano plots were generated to visualize the mRNA expression profiles between hypoxic and normoxic samples. (E and F) GO enrichment and KEGG analysis of differentially expressed mRNAs in HFL-1 cells cultured in the hypoxic and normoxic conditioned medium from HMC-1 cells. HFL-1, human lung fibroblasts; GO, Gene Ontology; KEGG, Kyoto Encyclopedia of Genes and Genomes; H, hypoxia; N, normoxia; HMC-1, human mast cells; HFL-1, human fetal lung fibroblasts.

in HFL-1 cells cultured in hypoxic conditioned medium from HMC-1 cells compared with HFL-1 cells cultured in normoxic conditioned medium (Fig. 6A and B). Similarly, the transition from fibroblast to myofibroblast induced by hypoxic conditioned medium from HMC-1 cells was identified by immunofluorescence, suggesting that mast cells are involved in the phenotypic switch of lung fibroblasts under hypoxia (Fig. 6C).
Increased mast cell numbers and activated extracellular matrix remodeling in the lungs of hypoxic rats. Histological analysis revealed that the thickness of pulmonary vessels in rats in the hypoxic group was increased compared with the normoxic controls, while their vascular lumens were narrowed (Fig. 7A). According to the toluidine blue in situ staining of lung specimens, an increased accumulation of mast cells was observed in the lungs of hypoxic rats (Fig. 7B). 
B
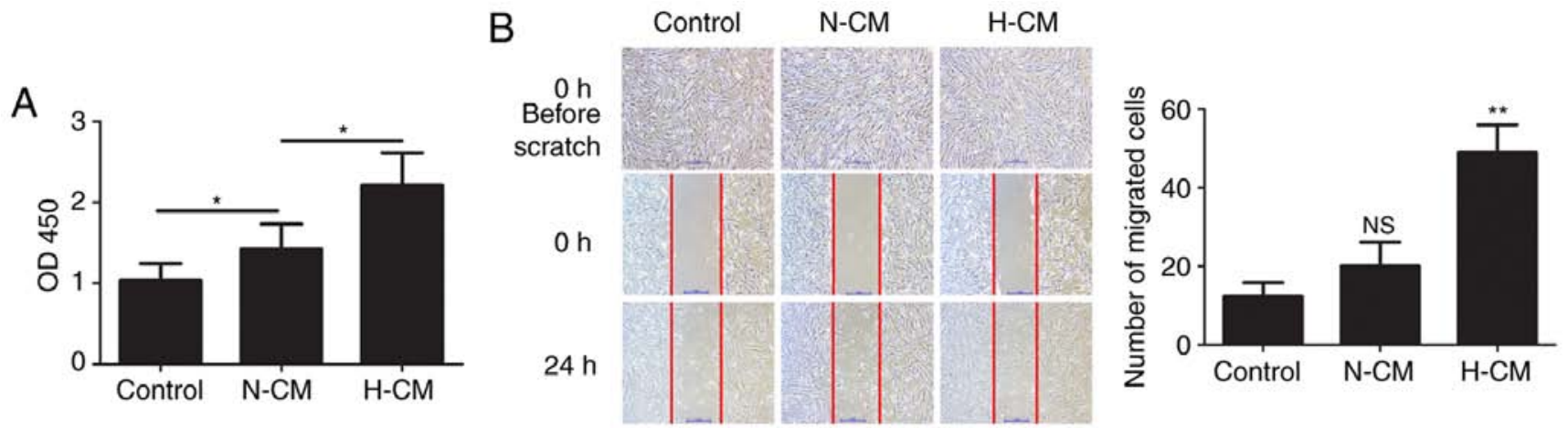

Figure 4. Effects of conditioned medium from HMC-1 cells on the proliferation and migration of HFL-1 cells. (A) After treatment with normoxic or hypoxic conditioned medium from HMC-1 cells, the proliferation of HFL-1 cells was assessed by the Cell Counting Kit-8 assay. (B) Migration of HFL-1 cells after culture in normoxic or hypoxic conditioned medium from HMC-1 cells was determined by scratch assay. Representative images before and after inflicting the wound are shown and quantified. There were 6 biological replicates/condition. Error bars depict the standard deviation. ${ }^{*} \mathrm{P}<0.05$, ${ }^{* *} \mathrm{P}<0.01$, NS, non-significant. Bar, $1 \mathrm{~mm}$. N-CM, normoxic conditioned medium; H-CM, hypoxic conditioned medium; HMC-1, human mast cells; HFL-1, human fetal lung fibroblasts.

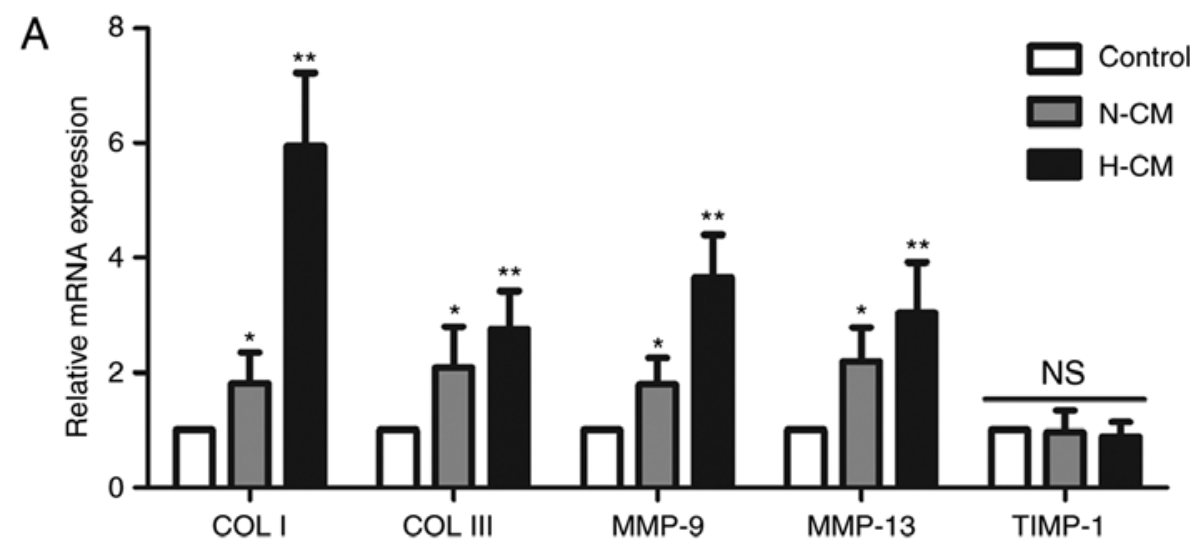

B
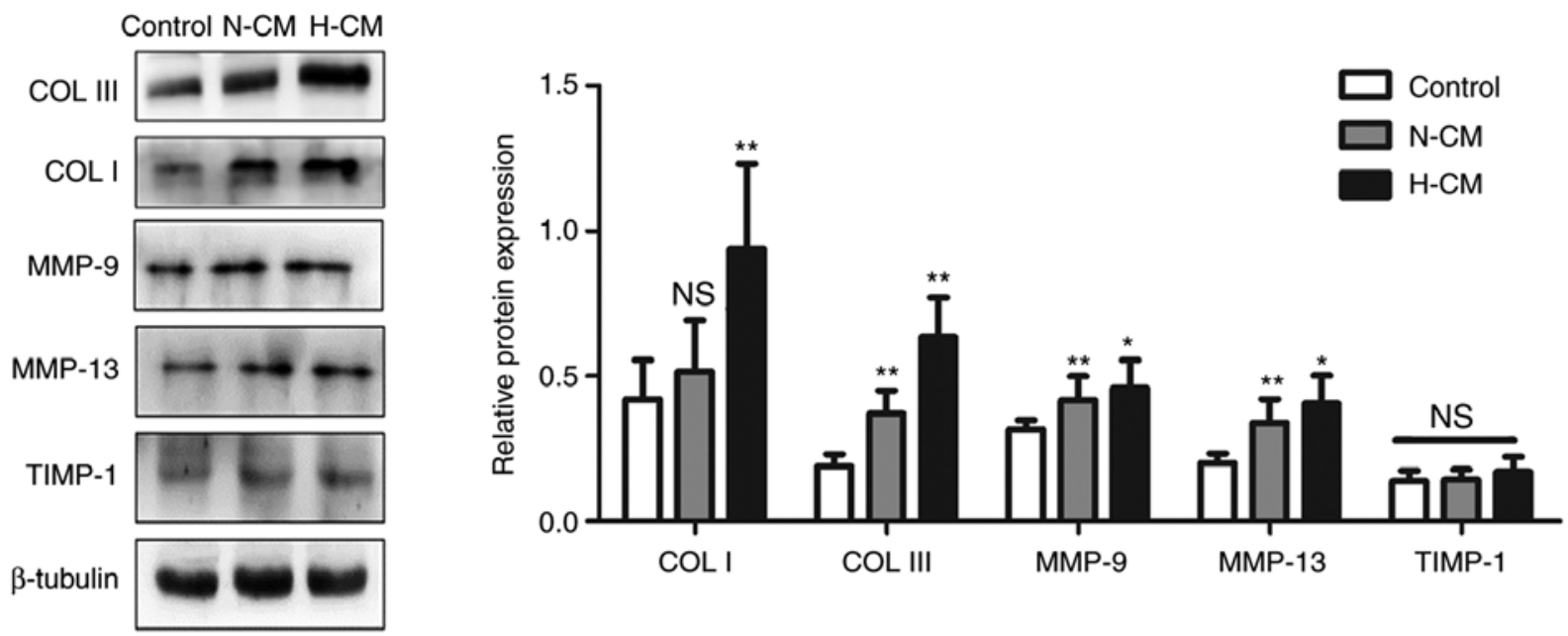

Figure 5. Effects of conditioned medium from HMC-1 cells on the production of collagens and MMPs by HFL-1 cells. (A) Following culture in normoxic or hypoxic conditioned medium from HMC-1 cells, the mRNA expression of collagen type I and III, MMP-9, MMP-13 and TIMP-1 in HFL-1 cells were assessed by reverse transcription-quantitative polymerase chain reaction analysis, normalized to the expression of $\beta$-tubulin, and expressed as fold change relative to the expression of the control group. (B) Western blot analysis of collagen type I and III, MMP-9, MMP-13 and TIMP-1 protein expression in HFL-1 cells cultured in conditioned medium from HMC-1 cells. There were 4 biological replicates/condition. Error bars depict the standard deviation. ${ }^{*} \mathrm{P}<0.05,{ }^{* *} \mathrm{P}<0.01, \mathrm{NS}$, not significant. COL I, collagen type I; COL III, collagen type III; MMP-9, matrix metalloproteinase-9; TIMP-1, tissue inhibitor of metalloproteinase-1; N-CM, normoxic conditioned medium; H-CM, hypoxic conditioned medium; HMC-1, human mast cells; HFL-1, human fetal lung fibroblasts.

Immunohistochemistry results revealed that the hypoxic group exhibited increased deposition of collagen I and III compared with the control group (Fig. 7C). Moreover, the protein expres- sion of the proteolytic enzymes MMP-9, MMP-13 and TIMP-1 was also increased in the lung tissues of hypoxic rats, indicating that hypoxia facilitates the accumulation of mast cells, 
A

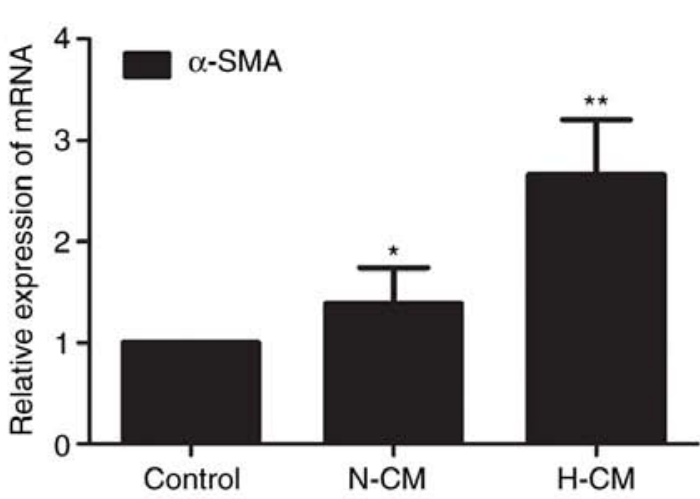

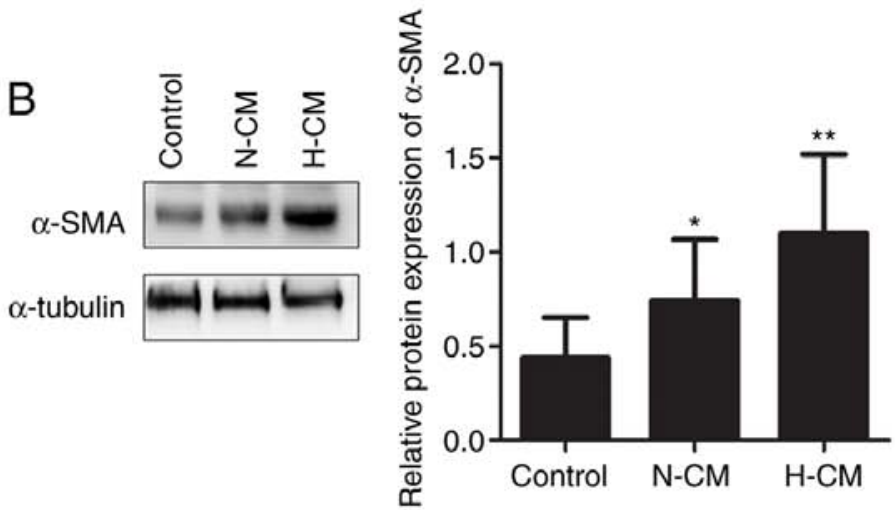

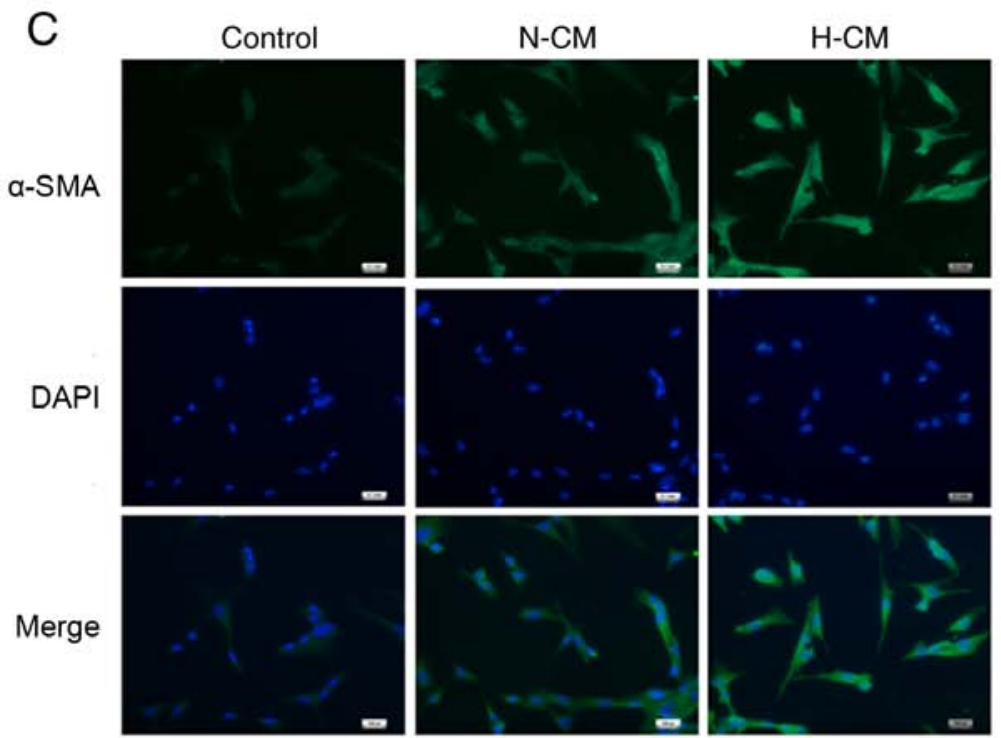

Figure 6. Effects of conditioned medium from HMC-1 cells on the transition of HFL-1 cells from fibroblasts to myofibroblasts. (A) After treatment with normoxic or hypoxic conditioned medium from HMC-1 cells, the expression of $\alpha$-SMA mRNA was determined by reverse transcription-quantitative polymerase chain reaction analysis. $\beta$-tubulin was used as an internal control. (B) Western blotting was performed to assess the level of $\alpha$-SMA protein in HFL-1 cells cultured in normoxic or hypoxic conditioned medium from HMC-1 cells. (C) After treatment with conditioned medium from HMC-1 cells, HFL-1 cells were stained for immunofluorescence for $\alpha$-SMA. Nuclei were counterstained with DAPI. There were 4-6 biological replicates/condition. Error bars represent the standard deviation. ${ }^{*} \mathrm{P}<0.05,{ }^{* *} \mathrm{P}<0.01$. Bar, $50 \mu \mathrm{m}$. $\alpha$-SMA, $\alpha$-smooth muscle actin; DAPI, 4',6-diamidino-2-phenylindole; HMC-1, human mast cells; HFL-1, human fetal lung fibroblasts.

and activates collagen metabolism and vascular remodeling in vivo (Fig. 7D).

\section{Discussion}

The normal pulmonary vascular system is well-organized and exhibits high compliance, but its physical structure is destroyed by pulmonary vascular remodeling in patients with pulmonary hypertension, which is characterized by increased vascular stiffness and reduced pulmonary arterial compliance (4). Resident pulmonary arterial fibroblasts are considered one of the key cells initiating and potentiating chronic hypoxic pulmonary vascular remodeling $(6,12)$. The mechanism responsible for the structural and functional changes in fibroblasts remains unclear. In the present study, increased proliferation and proinflammatory cytokine secretion by mast cells was observed under hypoxic conditions. RNA-seq identified 2,077 upregulated and 2,418 downregulated mRNAs in HFL-1 cells cultured in hypoxic conditioned medium from HMC-1 cells compared with normoxic controls, which are involved in various pathways, including extracellular matrix organization, cell proliferation and migration. To verify the effects of HMC-1 on HFL-1 cells, conditioned medium from hypoxic mast cells was found to increase the proliferation, migration capacity and collagen production in lung fibroblasts and trigger the phenotypic transition from fibroblasts to myofibroblasts. Similar pathological phenomena, including vascular remodeling, accumulation of mast cells and excessive deposition of collagen were observed in the lungs of hypoxic rats.

Mast cells are derived from CD34-expressing hematopoietic stem cells and have traditionally been recognized as sentinel cells in allergic and non-allergic immune responses under physiological conditions (13-15). Of note, accumulating evidence demonstrates that mast cells are involved in vascular remodeling through secretion of proangiogenic proteases and interaction with endothelial and smooth muscle cells, and they may be responsible for the development of pulmonary hypertension $(16,17)$. In the lungs of left heart disease model rats, mast cell activation is the most notable change in the 
A

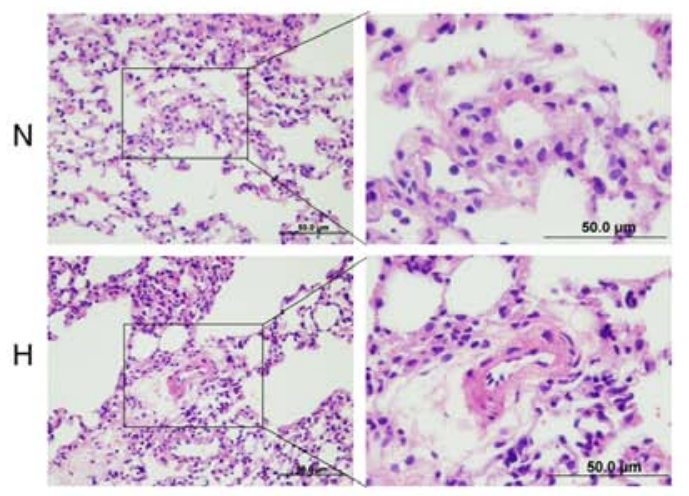

C

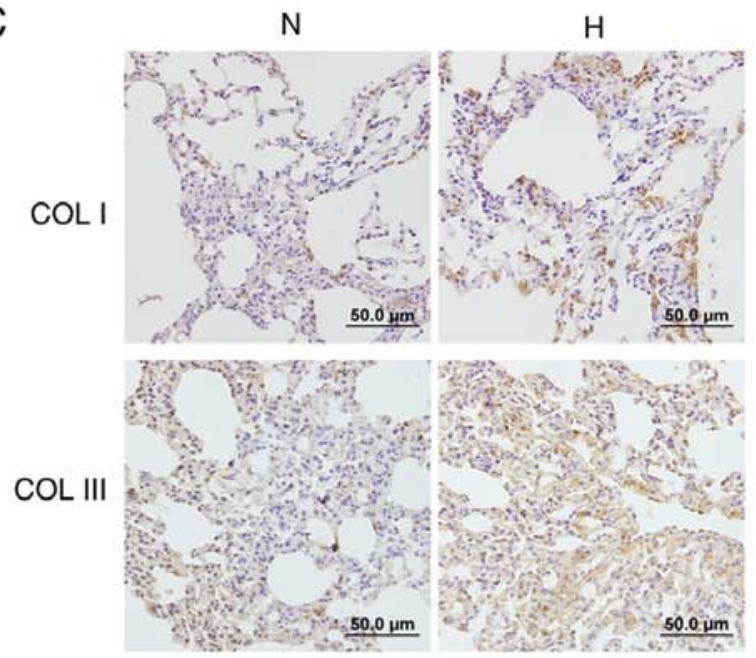

B

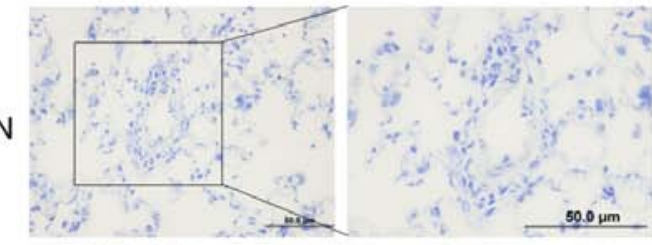

$\mathrm{H}$

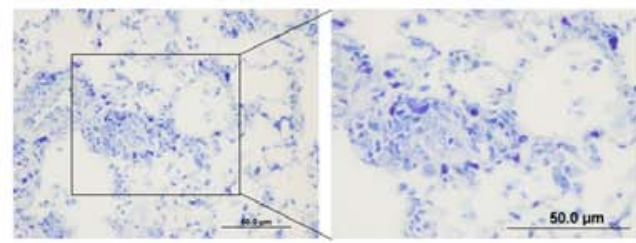

D

$\mathrm{N}$

$\mathrm{H}$
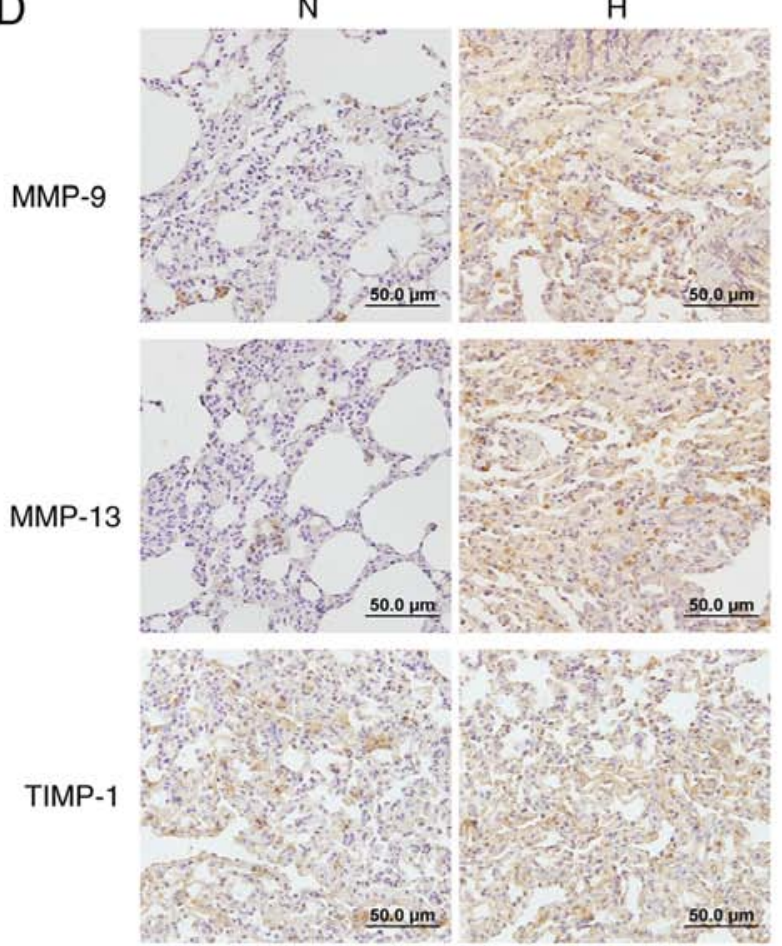

Figure 7. Effects of hypoxia on mast cells and ECM remodeling in rat lungs. (A) The pathological changes of pulmonary vessels in the rat lungs after exposure to hypoxia were examined by hematoxylin and eosin staining (magnification, $x 200$ and 400). (B) Toluidine blue staining demonstrated increased accumulation of mast cells in the lungs of hypoxic rats (magnification, x200 and 400). (C and D) The expression of collagen I, collagen III, MMP-9, MMP-13 and TIMP-1 in the lungs of rats after exposure to hypoxia was determined by immunohistochemistry staining (magnification, x200). ECM, extracellular matrix; MMP, matrix metalloproteinase; TIMP, tissue inhibitor of metalloproteinase; N, normoxic; $\mathrm{H}$, hypoxic.

pathological process of vascular remodeling and pulmonary hypertension, and these effects are largely attenuated in mast cell-deficient rats $(18,19)$. In the present study, hypoxia induced the proliferation of mast cells and increased mast cell infiltration in rat lungs with hypoxic pulmonary hypertension, which is in accordance with previous studies. Mast cells are found to be highly viable for up to 3 days under hypoxic conditions, and then the viability decreases for 5 to 7 days; it was also observed that hypoxia increases the secretion of IL- 6 by mast cells, but does not affect their degranulation (20). Vajner et al reported a significant increase in the number of mast cells in the walls of prealveolar arteries in the early stage of hypertension in the lungs of rats exposed to chronic hypoxia, and additional mast cell accumulation was detected within the walls of conduit arteries and subpleurally (21). IL-6 plays a critical role in pulmonary vascular remodeling and hypertension in hypoxic and monocrotaline-induced PAH models, and mast cells have been identified as the primary source of IL-6 (22). In the present study, it was observed that hypoxia facilitated the production and secretion of various cytokines, including IL-1 $\beta$, IL- 6 and TNF- $\alpha$, by mast cells. The early use of mast cell stabilizers may inhibit the release of all mediators, including proteases and proinflammatory factors, and reduce vascular remodeling in hypoxia-induced rodent pulmonary hypertension, suggesting that mast cells may be a potential target to arrest and reverse pulmonary vascular remodeling (23).

Under physiological conditions, the balance between proliferation and apoptosis of vascular cells contributes to the maintenance of the thickness of the vascular wall. If the equilibrium is disturbed, the overproliferating cells may obstruct the vessel lumen, resulting in vascular remodeling and increased pulmonary pressure. The adventitial fibroblast is a pivotal regulator of vascular wall function and performs 
biological functions, including proliferation, differentiation, synthesis and secretion of extracellular matrix and other mediators $(24,25)$. The activation of pulmonary adventitial fibroblasts contributes substantially to pulmonary vascular remodeling (8). It was reported that mast cells promote the viability of fibroblasts in several physiological and pathological processes. In idiopathic pulmonary fibrosis, tryptase from mast cells activates the protein kinase C- $\alpha /$ Raf-1/p44/42 signaling pathway in human lung fibroblasts and thus promotes their proliferation. In turn, fibroblasts induce mast cell activation and stimulate tryptase release (26). In the present study, we found that hypoxia-induced cytokine secretion from mast cells stimulated the proliferation and migration of lung fibroblasts. The proliferation of adventitial fibroblasts increases within hours of hypoxic exposure and fibroblasts can transform into myofibroblasts and migrate into the medial layer, or even into the intima, subsequently resulting in increased thickness of the vascular wall and reduced pulmonary arterial compliance. Moreover, it is hypothesized that certain angiogenic factors, including VEGF and PDGFR, may be involved in the pathological process of vascular remodeling and pulmonary hypertension. Further studies with in vivo and in vitro experiments to detect the expression of angiogenic factors are warranted. The transition from fibroblast to myofibroblast is a critical pathophysiological process in a variety of fibrotic diseases, including pulmonary hypertension (27). Accumulated myofibroblasts have been observed in the intimal lesions of patients with pulmonary hypertension (28). We herein observed that, compared with normoxic control medium, hypoxic conditioned medium from mast cells induced the proliferation and phenotypic transition of lung fibroblasts, indicating that the hypoxic microenvironment is another important trigger for the activation of fibroblasts and pulmonary vascular remodeling.

The imbalance of extracellular matrix synthesis and degradation also contributes to the structural remodeling of peripheral pulmonary arteries and aggravates the pathological process $(29,30)$. Active collagen synthesis, increased collagen accumulation and deposition in perivascular and intravascular compartments has been observed in patients and experimental models of pulmonary hypertension. It was reported that type I collagen was the earliest expressed gene and exhibited the largest increase in expression in the lungs of mice exposed to hypoxia, followed by type III collagen, type IV basement membrane collagen, MMPs and TIMPs, which increased with prolonged hypoxic exposure (31). Wang et al reported that the content of collagen not cross-linking in the pulmonary vasculature is associated with pulmonary artery remodeling and leads to proximal vascular stiffening and ventricular pulsatile overload in early pulmonary hypertension (32). The N-terminal propeptide of type III procollagen was found to be significantly elevated in the serum of patients with pulmonary hypertension and may predict the severity of the disease (33). In the present study, we found that hypoxic conditioned medium from mast cells stimulated fibroblasts to produce more type I and type III collagen. Moreover, disorganized expression of proteolytic enzymes, including MMP-9, MMP-13 and TIMP-1, in the pulmonary arteries is involved in pulmonary vascular remodeling. However, the change tendency of TIMP-1 expression in vivo differs from the in vitro results, which requires further investigation. Transgenic mice overexpressing MMP-9 exhibit aggravated pulmonary vascular remodeling and pulmonary hypertension following treatment with monocrotaline compared with wild-type mice (34). The level of circulating proteolytic enzymes, including MMP-9 and TIMP-1, was found to be dysregulated in patients with pulmonary hypertension (35). The present study demonstrated that hypoxic mast cells contribute to dysregulated extracellular matrix synthesis and degradation in vitro and in vivo.

The phenotypic alteration of lung fibroblasts activated by hypoxic conditioned medium from mast cells was consistent with our hypothesis that the multiple effects of the hypoxic microenvironment and mast cells on fibroblasts contribute to pulmonary vascular remodeling, and this process is likely one of the important mechanisms underlying the development of hypoxic pulmonary hypertension.

\section{Acknowledgements}

Not applicable.

\section{Funding}

The present study was supported by the National Natural Science Foundation of China (grant no. 81670043).

\section{Availability of data and materials}

The datasets used and/or analyzed during the present study are available from the corresponding author on reasonable request.

\section{Authors' contributions}

$\mathrm{XW}, \mathrm{LL}$ and $\mathrm{XL}$ conceived and designed the experiment. XW, $\mathrm{XC}, \mathrm{YW}$ and YL performed the experiments. XW and $\mathrm{XC}$ performed data analysis. XW, LL and XL prepared and wrote the manuscript. All authors have read and approved the final manuscript.

\section{Ethics approval and consent to participate}

All animal experiments were performed according to the Guide for the Care and Use of Laboratory Animals and were approved by the Peking University First Hospital Ethical Review Committee (approval no. J201533). All efforts were made to minimize animal suffering and the number of animals used.

\section{Patient consent for publication}

Not applicable.

\section{Competing interests}

The authors declare that they have no competing interests.

\section{References}

1. Grimminger J, Ghofrani HA, Weissmann N, Klose H and Grimminger F: COPD-associated pulmonary hypertension: Clinical implications and current methods for treatment. Exp Rev Respir Med 10: 755-766, 2016. 
2. Wang Z and Chesler NC: Pulmonary vascular mechanics: Important contributors to the increased right ventricular afterload of pulmonary hypertension. Exp Physiol 98: 1267-1273, 2013.

3. Nakagawa Y,Kishida K, Kihara S, Funahashi T and Shimomura I Adiponectin ameliorates hypoxia-induced pulmonary arterial remodeling. Biochem Biophys Res Commun 382: 183-188, 2009.

4. Thenappan T, Ormiston ML, Ryan JJ and Archer SL: Pulmonary arterial hypertension: Pathogenesis and clinical management. BMJ 360: j5492, 2018.

5. Sluiter I, van Heijst A, Haasdijk R, Kempen MB Boerema-de Munck A, Reiss I, Tibboel D and Rottier RJ: Reversal of pulmonary vascular remodeling in pulmonary hypertensive rats. Exp Mol Pathol 93: 66-73, 2012.

6. Di Wang H, Ratsep MT, Chapman A and Boyd R: Adventitial fibroblasts in vascular structure and function: The role of oxidative stress and beyond. Canadian J Physiol Pharmacol 88 177-186, 2010.

7. Lerner CA, Rutagarama P, Ahmad T, Sundar IK, Elder A and Rahman I: Electronic cigarette aerosols and copper nanoparticles induce mitochondrial stress and promote DNA fragmentation in lung fibroblasts. Biochem Biophys Res Commun 477: 620-625, 2016.

8. Chai X, Sun D, Han Q, Yi L, Wu Y and Liu X: Hypoxia induces pulmonary arterial fibroblast proliferation, migration, differentiation and vascular remodeling via the PI3K/Akt/p70S6K signaling pathway. Int J Mol Med 41: 2461-2472, 2018.

9. Marsh LM, Jandl K, Grunig G, Foris V, Bashir M, Ghanim B, Klepetko W, Olschewski H, Olschewski A and Kwapiszewska G: The inflammatory cell landscape in the lungs of patients with idiopathic pulmonary arterial hypertension. Eur Respir J 51: pii: 1701214, 2018

10. Kosanovic D, Dahal BK, Peters DM, Seimetz M, Wygrecka M, Hoffmann K, Antel J, Reiss I, Ghofrani HA, Weissmann N, et al: Histological characterization of mast cell chymase in patients with pulmonary hypertension and chronic obstructive pulmonary disease. Pulm Circ 4: 128-136, 2014.

11. Yang Y, Zhang Z, Zhang H, Hong K, Tang W, Zhao L, Lin H, Liu D, Mao J, Wu H and Jiang H: Effects of maternal acrolein exposure during pregnancy on testicular testosterone production in fetal rats. Mol Med Rep 16: 491-498, 2017

12. El Kasmi KC, Pugliese SC, Riddle SR, Poth JM, Anderson AL, Frid MG, Li M, Pullamsetti SS, Savai R, Nagel MA, et al: Adventitial fibroblasts induce a distinct proinflammatory/ profibrotic macrophage phenotype in pulmonary hypertension. J Immunol 193: 597-609, 2014

13. Mukai K, Tsai M, Saito $\mathrm{H}$ and Galli SJ: Mast cells as sources of cytokines, chemokines, and growth factors. Immunol Rev 282 $121-150,2018$

14. Shi GP, Bot I and Kovanen PT: Mast cells in human and experimental cardiometabolic diseases. Nat Rev Cardiol 12: 643-658, 2015.

15. Ko SC, Lee DS, Park WS, Yoo JS, Yim MJ, Qian ZJ, Lee CM, Oh J, Jung WK and Choi IW: Anti-allergic effects of a nonameric peptide isolated from the intestine gastrointestinal digests of abalone (Haliotis discus hannai) in activated HMC-1 human mast cells. Int J Mol Med 37: 243-250, 2016.

16. Pugliese SC, Poth JM, Fini MA, Olschewski A, El Kasmi KC and Stenmark KR: The role of inflammation in hypoxic pulmonary hypertension: From cellular mechanisms to clinical phenotypes. Am J Physiol Lung Cell Mol Physiol 308: L229-L252, 2015.

17. Moiseeva EP, Roach KM, Leyland ML and Bradding P: CADM1 is a key receptor mediating human mast cell adhesion to human lung fibroblasts and airway smooth muscle cells. PLoS One 8 : e61579, 2013

18. Zhu YJ, Kradin R, Brandstetter RD, Staton G, Moss J and Hales CA: Hypoxic pulmonary hypertension in the mast cell-deficient mouse. J Appl Physiol Respir Enviroc Exerci Physiol 54: 680-686, 1983.

19. Hoffmann J, Yin J, Kukucka M, Yin N, Saarikko I, Sterner-Kock A, Fujii H, Leong-Poi H, Kuppe H, Schermuly RT and Kuebler WM: Mast cells promote lung vascular remodelling in pulmonary hypertension. Eur Respir J 37: 1400-1410, 2011.
20. Gulliksson M, Carvalho RF, Ulleras E and Nilsson G: Mast cell survival and mediator secretion in response to hypoxia. PLoS One 5: e12360, 2010

21. Vajner L, Vytásek R, Lachmanová V, Uhlík J, Konrádová V, Novotná J, Hampl V and Herget J: Acute and chronic hypoxia as well as 7-day recovery from chronic hypoxia affects the distribution of pulmonary mast cells and their MMP-13 expression in rats. Int J Exp Pathol 87: 383-391, 2006.

22. Breitling S, Hui Z, Zabini D, Hu Y, Hoffmann J, Goldenberg NM, Tabuchi A, Dos Santos C and Kuebler WM: The mast cell-B cell axis in lung vascular remodeling and pulmonary hypertension. Am J Physiol Lung Cell Mol Physiol 312: L710-L721, 2017.

23. Bartelds B, van Loon RLE, Mohaupt S, Wijnberg H, Dickinson MG, Boersma B, Takens J, van Albada M and Berger RMF: Mast cell inhibition improves pulmonary vascular remodeling in pulmonary hypertension. Chest 141: 651-660, 2012.

24. Haurani MJ and Pagano PJ: Adventitial fibroblast reactive oxygen species as autacrine and paracrine mediators of remodeling: Bellwether for vascular disease? Cardiovas Res 75: 679-689, 2007.

25. Stenmark KR, Gerasimovskaya E, Nemenoff RA and Das M: Hypoxic activation of adventitial fibroblasts: Role in vascular remodeling. Chest 122: (6 Suppl) S326-S334, 2002.

26. Wygrecka M, Dahal BK, Kosanovic D, Petersen F, Taborski B, von Gerlach S, Didiasova M, Zakrzewicz D, Preissner KT, Schermuly RT and Markart P: Mast cells and fibroblasts work in concert to aggravate pulmonary fibrosis: Role of transmembrane SCF and the PAR-2/PKC-alpha/Raf-1/p44/42 signaling pathway. Am J Pathol 182: 2094-2108, 2013.

27. Short M, Nemenoff RA, Zawada WM, Stenmark KR and Das M: Hypoxia induces differentiation of pulmonary artery adventitial fibroblasts into myofibroblasts. Am J Physiol Cell Physiol 286: C416-C425, 2004

28. Farkas L, Gauldie J, Voelkel NF and Kolb M: Pulmonary hypertension and idiopathic pulmonary fibrosis: A tale of angiogenesis, apoptosis, and growth factors. Am J Respir Cell Mol Biol 45: $1-15,2011$.

29. Thenappan T, Chan SY and Weir EK: Role of extracellular matrix in the pathogenesis of pulmonary arterial hypertension. Am J Physiol Heart Circ Physiol 315: H1322-H1331, 2018.

30. Liu P, Yan S, Chen M, Chen A, Yao D, Xu X, Cai X, Wang L and Huang X: Effects of baicalin on collagen Iota and collagen IotaIotaIota expression in pulmonary arteries of rats with hypoxic pulmonary hypertension. Int J Mol Med 35: 901-908, 2015.

31. Estrada KD and Chesler NC: Collagen-related gene and protein expression changes in the lung in response to chronic hypoxia. Biomech Model Mechanobiol 8: 263-272, 2009.

32. Wang Z, Schreier DA, Abid H, Hacker TA and Chesler NC: Pulmonary vascular collagen content, not cross-linking, contributes to right ventricular pulsatile afterload and overload in early pulmonary hypertension. J Appl Physiol (1985) 122: 253-263, 2017.

33. Safdar Z, Tamez E, Frost A, Guffey D, Minard CG and Entman ML: Collagen metabolism biomarkers and health related quality of life in pulmonary arterial hypertension. Int J Cardiovas Res 4, 2015.

34. George $\mathrm{J}$ and D'Armiento J: Transgenic expression of human matrix metalloproteinase-9 augments monocrotaline-induced pulmonary arterial hypertension in mice. J Hypertens 29: 299-308, 2011

35. Safdar Z, Tamez E, Chan W, Arya B, Ge Y, Deswal A, Bozkurt B Frost $\mathrm{A}$ and Entman M: Circulating collagen biomarkers as indicators of disease severity in pulmonary arterial hypertension. JACC Heart Fail 2: 412-421, 2014.

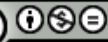

This work is licensed under a Creative Commons Attribution-NonCommercial-NoDerivatives 4.0 International (CC BY-NC-ND 4.0) License. 